\title{
HIV1 p24 Antigen Neutralization
}

National Cancer Institute

\section{Source}

National Cancer Institute. HIV1 p24 Antigen Neutralization. NCI Thesaurus. Code C95523.

An assay used to confirm the presence of HIV1 p24 antigen in a blood sample. Following repeated positive results by a virus-specific enzyme immunosorbant assay, free antibodies specific for HIV1 p24 are added to the assay and should react with the viral protein and block a subsequent enzyme immunosorbant assay. 